\title{
APLICAÇÃO DE CALCÁRIO COM DIFERENTES GRAUS DE REATIVIDADE: ALTERAÇÕES QUÍMICAS NO SOLO CULTIVADO COM MILHO(1)
}

\author{
Suzana Romeiro Araújo( ${ }^{(2)}$, José Alexandre Melo Demattê ${ }^{(3)} \&$ \\ Fernando José Garbuio ${ }^{(4)}$
}

\begin{abstract}
RESUMO
Com a correção da acidez, nutrientes importantes para o cultivo do milho tornam-se mais disponíveis à planta, promovendo o aumento de produtividade. Objetivou-se com este estudo avaliar as alterações químicas ocorrentes em dois solos e na produção de matéria seca de milho pela aplicação de corretivos com diferentes graus de reatividade. Foi realizado um primeiro experimento em casa de vegetação, aplicando-se doses de três calcários comerciais, sendo um com reatividade média, denominado A $(\mathrm{RE}=85,7 \%$; PRNT $=88,3 \%)$, outro com reatividade baixa denominado $\mathrm{B}(\mathrm{RE}=83,7 \%$; $\mathrm{PRNT}=76,2 \%)$, e outro, denominado $\mathrm{C}(\mathrm{RE}=99,1 \%$; PRNT $=105,3 \%)$ altamente reativo, em quatro cultivos sucessivos de milho. Os solos utilizados foram Neossolo Quartzarênico e Latossolo Vermelho. Os tratamentos foram dispostos inteiramente ao acaso, com quatro repetições, constando de três doses de calcário, calculadas para elevar a saturação por bases para 40,60 e $80 \%$, além da testemunha. Paralelamente, um experimento de incubação foi realizado para verificar o efeito residual dos corretivos ao longo do

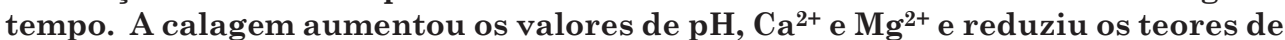
$\mathrm{Al}^{3+}$ trocável. O melhor crescimento do milho foi observado no Latossolo Vermelho. Neste solo, os calcários A e B foram mais eficientes na elevação do pH durante os quatro cultivos, enquanto o produto $\mathrm{C}$ teve menor eficiência na redução do $\mathrm{Al}^{3+}$ nos últimos ciclos, devido à sua maior reatividade. Os calcários A e C tiveram comportamentos semelhantes nos dois solos estudados. Houve queda na produção de matéria seca aérea com os cultivos sucessivos de milho. No experimento de incubação, os teores de Ca trocável foram maiores que os residuais.
\end{abstract}

Termos de indexação: calagem, efeito residual, Zea mays.

\footnotetext{
(1) Parte da Dissertação de Mestrado do primeiro autor apresentada à Escola Superior de Agricultura “Luiz de Queiroz", Universidade de São Paulo - ESALQ/USP. Recebido para publicação em novembro de 2008 e aprovado em agosto de 2009.

${ }^{(2)}$ Doutoranda em Agronomia, Escola Superior de Agricultura "Luiz de Queiroz" - ESALQ/USP. Av. Pádua Dias 11, Caixa Postal 9, CEP 13418-900 Piracicaba (SP). Bolsista PIBIC/CNPq. E-mail: suzanaromeiro@yahoo.com.br

(3) Professor do Departamento de Solos e Nutrição de Plantas, ESALQ/USP. E-mail: jamdemat@carpa.ciagri.usp.br

(4) Doutorando em Agronomia, ESALQ. Bolsista Fapesp. E-mail: fgarbuio@yahoo.com.br
} 


\title{
SUMMARY: APPLICATION OF LIME WITH DIFFERENT REACTION DEGREES: CHEMICAL CHANGES IN SOIL UNDER CORN
}

\begin{abstract}
With acidity correction, important nutrients for the corn development become more available to the plants, increasing yield. The objective of this study was to evaluate chemical changes in two soils and corn dry matter yield as affected by lime application with different degrees of reaction. The experiment was carried out in a greenhouse on a Oxisol and a Quartzpsament. Three rates of three commercial limes were applied, one with mean reactivity $A(R E=85.7 \% ; P R N T=88.3 \%)$, another with low reactivity $B(R E=83.7 \% ; P R N T=$ $76.2 \%)$ and $C(R E=99.1 \% ; P R N T=105.3 \%)$ with high reactivity, in four successive corn cycles. A randomized complete block design was used with four replications. The treatments consisted of three lime rates, calculated to increase base saturation to 40, 60 and $80 \%$, plus a control treatment. In parallel, another experiment was performed to verify the residual lime effect over time by incubation. Liming increased the values of $\mathrm{pH}, \mathrm{Ca}^{2+}$ and $\mathrm{Mg}^{2+}$ and reduced $A l^{3+}$. The best corn development was observed on the Oxisol. In this soil, the limes A and B were more efficient to increase the $\mathrm{pH}$ throughout the cycles, whereas product $C$ had the lowest efficiency in $\mathrm{Al}^{3+}$ reduction in the last cycles due its higher reactivity degree. Limes $A$ and $C$ performed similarly in both soils. The shoot dry matter yield declined in the course of the successive corn cycles. In the incubation experiment, the exchangeable calcium content was higher than the residual.
\end{abstract}

Index terms: liming, residual effect, Zea mays.

\section{INTRODUÇÃO}

Os solos brasileiros, em sua maioria, são ácidos, destacando-se aqueles sob vegetação de Cerrado. Esses solos são caracterizados por baixos teores de $\mathrm{Ca}^{2+} \mathrm{e}$ $\mathrm{Mg}^{2+}$, teores elevados de $\mathrm{Al}^{3+}$, além da baixa disponibilidade de P. A acidez natural desses solos é proporcionada por diversos fatores, como material de origem com baixo teor de cátions básicos; precipitação pluvial maior que a evapotranspiração, acarretando lixiviação de bases no perfil (Fageria \& Gheyi, 1999); absorção de nutrientes catiônicos, na qual as plantas liberam quantidades equivalentes de hidrogênio $\left(\mathrm{H}^{+}\right)$; e acidificação proporcionada pela aplicação de fertilizantes, principalmente de nitrogenados (Malavolta, 1984; Vitti \& Luz,1997).

A calagem é uma das práticas menos dispendiosas e efetivas na correção da acidez e fornece $\mathrm{Ca}$ e $\mathrm{Mg}$ (Werner, 1986). Além disso, essa prática aumenta a disponibilidade de $\mathrm{P}$ e reduz a toxidez por $\mathrm{Al}$ e $\mathrm{Mn}$ no solo (Carvalho-Puppatto et al., 2004; Caires et al., 2008). Devido à baixa solubilidade do calcário, sua ação neutralizante depende da superfície de contato e do tempo de reação com o solo.

$\mathrm{O}$ aumento do $\mathrm{pH}$ do solo altera a disponibilidade de nutrientes, causando aumento na absorção de $\mathrm{N}$ (Goodroad \& Jellum, 1988), P, K, Ca e Mg (Lutz Jr. et al., 1972; Caires et al., 2002) pelo milho. São vários os trabalhos que demonstram aumentos consideráveis na produção de milho com a aplicação de calcário incorporado ao solo em sistema de preparo convencional (Gonzales-Erico et al., 1979; Camargo et al., 1982; Raij et al., 1983; Ernani et al., 1998). Quanto ao ganho na produção de matéria seca e de grãos, a calagem é uma prática destacada nos trabalhos de Forestieri \& De-Polli (1990) e Nwachuku \& Loganathan (1991), os quais concluíram que, além do aumento da produção de grãos, houve aumentos significativos dos teores de Ca e Mg na matéria seca de folhas e colmos de milho.

Das características relacionadas com a qualidade dos corretivos da acidez, apenas duas têm sido consideradas: o teor de neutralizantes e a granulometria. A granulometria tem sido determinada em termos de capacidade de reação no solo por curtos períodos de tempo, desconsiderando-se o efeito residual. A reatividade apresenta apenas uma relação parcial com a qualidade, não devendo refletir necessariamente na eficiência de um corretivo. Nesse sentido, a determinação das frações não trocáveis de $\mathrm{Ca}$ e $\mathrm{Mg}$ no solo, que teoricamente representam a fração do corretivo remanescente, que ainda não foi dissolvido ("calcário residual") (Raij et al., 1982; Quaggio et al., 1982, 1995), aliada às características químicas contidas na análise de fertilidade, é uma ferramenta importante para definição do momento correto para reaplicação do corretivo (Raij et al., 1982; Quaggio et al., 1982; Lima, 2004; Soratto \&Crusciol, 2008).

Dessa forma, espera-se que os calcários menos reativos promovam maior efeito de correção no solo em longo prazo. Assim, com o objetivo de avaliar as alterações químicas em dois solos cultivados com milho, foi realizado um experimento em casa de vegetação aplicando-se doses de calcários com 
diferentes graus de reatividade em quatro cultivos sucessivos. Foi também instalado um experimento de incubação com os calcários, no qual foi avaliado o efeito residual destes durante um período de 180 dias.

\section{MATERIAL E MÉTODOS}

O experimento foi conduzido no município de Piracicaba, São Paulo, em casa de vegetação. O híbrido de milho utilizado foi o cultivar DOW 2B710, safra 2006/2006, obtido em Jardinópolis/SP (germinação: 85 \% e pureza mínima: $98 \%$ ). Foram realizados quatro ciclos de cultivo, sendo o primeiro em maio de 2007, colocando-se oito sementes por vaso de $4 \mathrm{dm}^{3}$; após o estabelecimento das plântulas, efetuou-se o desbaste, mantendo-se duas plantas por vaso durante 57 dias após a emergência. Paralelamente, foi realizado um experimento de incubação sem a cultura, no qual foi avaliado o efeito residual dos corretivos.

Os solos utilizados no experimento foram um Latossolo Vermelho (LV) e um Neossolo Quartzarênico (RQ), coletados na camada de $0-20 \mathrm{~cm}$. Análises químicas (Raij et al., 1986, 1987) realizadas antes da instalação do experimento revelaram os seguintes resultados: $\mathrm{pH}\left(\mathrm{em} 0,01 \mathrm{~mol} \mathrm{~L}^{-1} \mathrm{CaCl}_{2}\right)=3,9 ; \mathrm{MO}=$ $31 \mathrm{~g} \mathrm{dm}^{-3} ; \mathrm{P}$ (resina) $=3 \mathrm{mg} \mathrm{dm}^{-3} ; \mathrm{Ca}^{2+}=7 \mathrm{mmol}_{\mathrm{c}} \mathrm{dm}^{-3}$; $\mathrm{Mg}^{2+}=3 \mathrm{mmol}_{\mathrm{c}} \mathrm{dm}^{-3} ; \mathrm{K}=0,6 \mathrm{mmol}_{\mathrm{c}} \mathrm{dm}^{-3} ; \mathrm{H}+\mathrm{Al}=$ $88 \mathrm{mmol}_{\mathrm{c}} \mathrm{dm}^{-3} ; \mathrm{Al}^{3+}=13 \mathrm{mmol}_{\mathrm{c}} \mathrm{dm}^{-3} ; \mathrm{CTC}=$ $98,6 \mathrm{mmol}_{\mathrm{c}} \mathrm{dm}^{-3} ; \mathrm{V}=10,8 \%$, para o Latossolo Vermelho; e pH (em 0,01 $\left.\mathrm{mol} \mathrm{L}^{-1} \mathrm{CaCl}_{2}\right)=4,1 ; \mathrm{MO}=$ $12 \mathrm{~g} \mathrm{dm}^{-3} ; \mathrm{P}=11 \mathrm{mg} \mathrm{dm}{ }^{-3} ; \mathrm{Ca}^{2+}=1 \mathrm{mmol}_{\mathrm{c}} \mathrm{dm}^{-3} ; \mathrm{Mg}^{2+}$ $=1 \mathrm{mmol}_{\mathrm{c}} \mathrm{dm}^{-3} ; \mathrm{K}=0,07 \mathrm{mmol}_{\mathrm{c}} \mathrm{dm}^{-3} ; \mathrm{H}+\mathrm{Al}=$ $28 \mathrm{mmol}_{\mathrm{c}} \mathrm{dm}^{-3} ; \mathrm{Al}^{3+}=5 \mathrm{mmol}_{\mathrm{c}} \mathrm{dm}^{-3} ; \mathrm{CTC}=$ $30,07 \mathrm{mmol}_{\mathrm{c}} \mathrm{dm}^{-3} ; \mathrm{V}=6,9 \%$, para o Neossolo Quartzarênico.

Antes da semeadura do milho, as amostras de solos foram secas ao ar, destorroadas, passadas em peneira de malha de $4 \mathrm{~mm}$ e acondicionadas em vasos de $4 \mathrm{dm}^{3}$ de capacidade. Em seguida foi realizada a calagem, com posterior incorporação do calcário apenas no primeiro ciclo da cultura. Foram utilizados três produtos comerciais, todos calcários dolomíticos, identificados como A, B e C, sendo produtos de média, baixa e alta reatividade, respectivamente (Quadro 1). As doses de calcário aplicadas foram: 0, 2,3, 4,6 e $6,9 \mathrm{t} \mathrm{ha}^{-1}$ para o LV e 0, 1,0, 1,6 e 2,2 $\mathrm{t} \mathrm{ha}^{-1}$ no NQ, considerando PRNT de $100 \%$. As doses foram calculadas para elevar a saturação por bases $(\mathrm{V} \%)$ a 40,60 e $80 \%$.

Após 30 dias da calagem, foram adicionados adubos minerais, sendo as doses calculadas conforme a necessidade da cultura. Para a adubação nitrogenada e a fosfatada, seguiu-se a recomendação de Malavolta (1980), com a aplicação de $400 \mathrm{~kg} \mathrm{ha}^{-1}$ de $\mathrm{N}$ e $400 \mathrm{~kg} \mathrm{ha}^{-1}$ de P. Na semeadura, aplicaram-se o equivalente a $1,68 \mathrm{t} \mathrm{ha}^{-1}$ de superfosfato simples, $1,58 \mathrm{t} \mathrm{ha}^{-1}$ de superfosfato triplo e $0,44 \mathrm{t} \mathrm{ha}^{-1}$ de ureia $(45 \% \mathrm{~N})$. O restante da dose de $\mathrm{N}$ foi aplicado em cobertura, aos 25 e 40 dias após a emergência das plântulas (DAE), na forma de sulfato de amônio e ureia. $\mathrm{O} \mathrm{K}$ foi aplicado na forma de $\mathrm{KCl}\left(0,76 \mathrm{t} \mathrm{ha}^{-1}\right)$. Os micronutrientes foram aplicados em solução, $20 \mathrm{~kg} \mathrm{ha}^{-1}$ de $\mathrm{MnSO}_{4} \cdot \mathrm{H}_{2} \mathrm{O}, \mathrm{ZnSO}_{4} \cdot 7 \mathrm{H}_{2} \mathrm{O}$ e $\mathrm{Fe}\left(\mathrm{NH}_{4}\right)_{2}\left(\mathrm{SO}_{4}\right)_{2} \cdot 6 \mathrm{H}_{2} \mathrm{O}$; $10 \mathrm{~kg} \mathrm{ha}^{-1} \mathrm{de}_{3} \mathrm{BO}_{3}$ e $\mathrm{CuSO}_{4} .5 \mathrm{H}_{2} \mathrm{O}$; e $2 \mathrm{~kg} \mathrm{ha}^{-1}$ de $\left(\mathrm{NH}_{4}\right)_{6} \mathrm{Mo}_{7} \mathrm{O}_{24} \cdot 4 \mathrm{H}_{2} \mathrm{O}$.

O delineamento experimental foi inteiramente casualizado em esquema fatorial, com quatro repetições. Os tratamentos foram: três doses e três fontes de calcário, além da testemunha, totalizando 80 vasos. Aos 57 dias após emergência (para todos os ciclos), as plantas foram colhidas em pleno florescimento, ou seja, no pico de acúmulo de matéria seca e máximo crescimento vegetativo. Após colhidas, foram secas em estufa até atingirem massa constante e efetuada a pesagem para determinação da produção de matéria seca de folhas e colmos. Logo após a colheita de um ciclo, o solo era preparado para novo plantio, sem no entanto fazer calagem.

No experimento de incubação foram utilizados $400 \mathrm{~g}$ de solo, e as doses de calcário também foram calculadas considerando a elevação da saturação por bases para 40, 60 e $80 \%$. O estudo durou 180 dias, e a cada dois dias os solos foram umedecidos com água, mantendo-se a umidade a $70 \%$ da capacidade de campo. Foram realizadas análises químicas para determinação dos teores de $\mathrm{Ca}$ e $\mathrm{Mg}$ trocáveis e residuais a cada 60 dias.

\section{Quadro 1. Caracterização química dos calcários utilizados no experimento}

\begin{tabular}{|c|c|c|c|c|c|c|c|c|c|c|c|}
\hline \multirow[t]{2}{*}{ Calcário } & \multirow[t]{2}{*}{$\mathrm{CaO}$} & \multirow[t]{2}{*}{$\mathrm{MgO}$} & \multirow{2}{*}{$\begin{array}{r}\mathrm{CaCO}_{3} \\
\%-\end{array}$} & \multirow{2}{*}{$\mathrm{MgCO}_{3}$} & \multirow{2}{*}{$\begin{array}{c}\begin{array}{c}\text { Sílica e } \\
\text { insolúveis }\end{array} \\
\end{array}$} & \multicolumn{3}{|c|}{$\begin{array}{c}\text { Tyler (Mesh)/Abertura } \\
\text { (mm) }\end{array}$} & \multirow{3}{*}{$\begin{array}{c}\text { PRNT } \\
88,3\end{array}$} & \multirow{3}{*}{$\begin{array}{c}\text { PN } \\
-\% \\
104,4\end{array}$} & \multirow{2}{*}{$\begin{array}{r}\text { RE } \\
\\
\end{array}$} \\
\hline & & & & & & $10 / 2,000$ & $20 / 0,840$ & $50 / 0,297$ & & & \\
\hline $\mathrm{A}$ & 30,8 & 20,9 & 55,1 & 51,9 & 4,0 & 99,7 & 91,4 & 73,0 & & & 85,7 \\
\hline B & 28,9 & 17,2 & 51,7 & 42,6 & 14,8 & 99,8 & 91,4 & 67,9 & 76,2 & 91,0 & 83,7 \\
\hline $\mathrm{C}$ & 32,5 & 18,9 & 58,3 & 46,9 & 2,1 & 100,0 & 100,0 & 97,8 & 105,3 & 106,2 & 99,1 \\
\hline
\end{tabular}


Nas amostras de solo foram determinados o $\mathrm{pH}$ em $\mathrm{CaCl}_{2}$ 0,01 mol L-1, C orgânico (método colorimétrico), $\mathrm{P}, \mathrm{Ca}^{2+}, \mathrm{Mg}^{2+} \mathrm{e} \mathrm{K}^{+}$resina trocadora de íons (Raij et al., 1986), $\mathrm{Al}^{3+}\left(\mathrm{KCl} 1 \mathrm{~mol} \mathrm{~L}^{-1}\right)$ e $\mathrm{H}+\mathrm{Al}$ (Raij et al., 1987). A determinação do calcário residual no solo foi realizada de acordo com Quaggio et al. (1995). Em tubo percolador foram colocados $10 \mathrm{~cm}^{3}$ de solo, entre papéis-filtro, sendo posteriormente percolados $100 \mathrm{~mL}$ da solução de $\mathrm{KCl}$ pela amostra (primeira extração, Ca e Mg trocáveis). Após a primeira extração, o solo foi transferido para um erlenmeyer e adicionaram-se $30 \mathrm{~mL}$ de $\mathrm{H}_{2} \mathrm{O}+50 \mathrm{~mL}$ de $\mathrm{HCl}$ 0,8 $\mathrm{mol} \mathrm{L}^{-1}$. O conjunto foi fervido em chapa aquecedora por cinco minutos a $200{ }^{\circ} \mathrm{C}$. Dessa forma, mediante a fervura do solo, juntamente com a ação do $\mathrm{HCl}$, o corretivo remanescente foi forçado a reagir. Na sequência, após resfriamento, o material foi filtrado (segunda extração, Ca e Mg residuais). A determinação de $\mathrm{Ca}$ e $\mathrm{Mg}$ nos extratos foi realizada por espectrometria de absorção atômica, diluindo as amostras com cloreto de lantânio, a fim de evitar a interferência do fosfato (Evans \& Grimshaw, 1968).

Os resultados foram submetidos à análise de variância e de regressão polinomial. Foram ajustadas equações de regressão aos dados obtidos de acordo com as doses de calcário, adotando-se como critério para escolha do modelo a magnitude dos coeficentes de determinação significativos a $5 \%$. Os tipos de calcário foram comparados por meio do teste de Tukey $(p=0,05)$ nos dois experimentos.

\section{RESULTADOS E DISCUSSÃO}

A calagem aumentou linearmente o $\mathrm{pH}$ dos solos nos quatro ciclos de cultivo, tanto para o solo argiloso (LV) (Figura 1) quanto para o arenoso (RQ) (Figura 2), independentemente do tipo de calcário aplicado. Não ocorreu interação significativa entre as doses de calcário e os ciclos de cultivo, ou seja, o comportamento das doses de calcário foi semelhante nos quatro ciclos. $\mathrm{O}$ aumento do $\mathrm{pH}$ do solo com a calagem resultou na redução linear dos teores de $\mathrm{Al}^{3+}$ trocável para ambos os solos (Figuras 1 e 2), devido à precipitação do $\mathrm{Al}^{3+}$ na forma de $\mathrm{Al}(\mathrm{OH})_{3}$ (Kinraid, 1991). De acordo com Abreu Jr. et al. (2003), que investigaram os componentes da acidez e suas relações com os atributos químicos de 26 solos de diferentes regiões brasileiras, os teores de $\mathrm{Al}^{3+}$ diminuíram com o aumento do $\mathrm{pH}$ até 5,5. $\mathrm{Em} \mathrm{pH}$ menor que 5,5 os compostos de $\mathrm{Al}^{3+}$ passam a ser reativos, dificultando a absorção e o transporte de nutrientes, como o P, K, Ca e Mg (Malavolta, 1984).

Os teores de $\mathrm{Ca}$ e $\mathrm{Mg}$ trocáveis, bem como a saturação por bases, aumentaram de forma linear com as doses de calcário aplicadas em ambos os solos (Figuras 1 e 2) e de forma semelhante em todos os ciclos de cultivo avaliados. Independentemente dos tratamentos, o pH, os teores trocáveis de Ca e Mg e a saturação por bases diminuíram com a sucessão dos cultivos para os dois tipos de solo (Figuras 3 e 4). Resultados semelhantes foram observados por Moreira et al. (2005) em um experimento de calagem para produção de alfafa, no qual houve redução média de 21, 33 e 58 \% nos valores de $\mathrm{pH}$, Ca e Mg trocáveis, respectivamente, do plantio até o sexto corte da forrageira. Como $\mathrm{Ca}$ e $\mathrm{Mg}$ foram fornecidos apenas no início do experimento pela calagem, a absorção desses nutrientes pelas plantas com os cultivos sucessivos proporcionou a reacidificação do solo. Com a remoção do Ca e Mg da solução do solo pelas raízes das plantas e, consequentemente, devido ao equilíbrio químico entre as fases sólida e líquida, a remoção do complexo

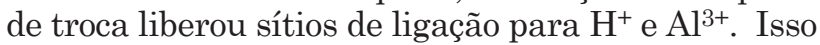
pode ser observado no teor de $\mathrm{Al}^{3+}$, o qual aumentou em consequência dos cultivos sucessivos. Em média, comparando os teores de $\mathrm{Al}^{3+}$ do primeiro e do último cultivo, eles aumentaram em $5,10 \mathrm{mmol}_{\mathrm{c}} \mathrm{dm}^{-3}$ no LV e $0,14 \mathrm{mmol}_{\mathrm{c}} \mathrm{dm}^{-3}$ no RQ (Figuras 3 e 4).

Entre os calcários testados no LV, o calcário C (PRNT $=105,3 \%$ ) foi o mais eficiente em aumentar o $\mathrm{pH}$ do solo, seguido pelo calcário A (PRNT $=88,3 \%$ ), que teve efeito semelhante ao do calcário $\mathrm{B}(\mathrm{PRNT}=$ $76,2 \%$ ), com exceção do primeiro ciclo, no qual o A foi o menos eficiente (Figura 3). A diferença entre os calcários observada na elevação do $\mathrm{pH}$ do solo não foi constatada nos teores de Al trocável, em que os corretivos não diferiram estatisticamente, exceto após o último cultivo, em que o calcário $\mathrm{C}$, mais reativo, resultou em menores valores de $\mathrm{Al}$ (Figura 3).

No LV, a dose 3 (calculada para elevar a saturação por bases para $80 \%$ ) foi a que apresentou maiores teores de Ca trocável; o calcário B (baixa reatividade) forneceu as maiores concentrações no primeiro ciclo e, diferentemente do que se esperava, atingiu menores concentrações no último. Os calcários A e C tiveram comportamentos semelhantes, sendo o A (reatividade média) mais eficiente no fornecimento de $\mathrm{Mg}^{2+}$, uma vez que possui maiores percentagens de $\mathrm{MgO}$ e $\mathrm{MgCO}_{3}$ em sua composição (Quadro 1). Cabe ressaltar que, independentemente do tipo e da dose de calcário

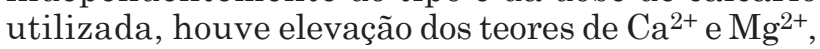
que eram muito baixos.

No solo de textura mais argilosa, os maiores teores de saturação por bases foram encontrados no primeiro ciclo com o uso de todos os calcários, sendo o produto $\mathrm{C}$ o que atingiu os maiores valores de saturação nos dois primeiros cultivos (Figura 3). No entanto, após o quarto ciclo de cultivo da planta, não houve diferenças significativas entre eles. É pertinente comentar o poder-tampão deste solo, uma vez que a calagem fora calculada para elevar a saturação por bases para $80 \%$ $\mathrm{e}$, neste trabalho, não atingiu valores superiores a $60 \%$. Soratto et al. (2008) também não atingiram os valores de $\mathrm{V} \%$ calculados por esse método em sistema de semeadura direta. Ocorreu redução do V \% a cada ciclo, e, após o quarto cultivo, a saturação por bases foi maior com uso do calcário A, que por sua vez possui 

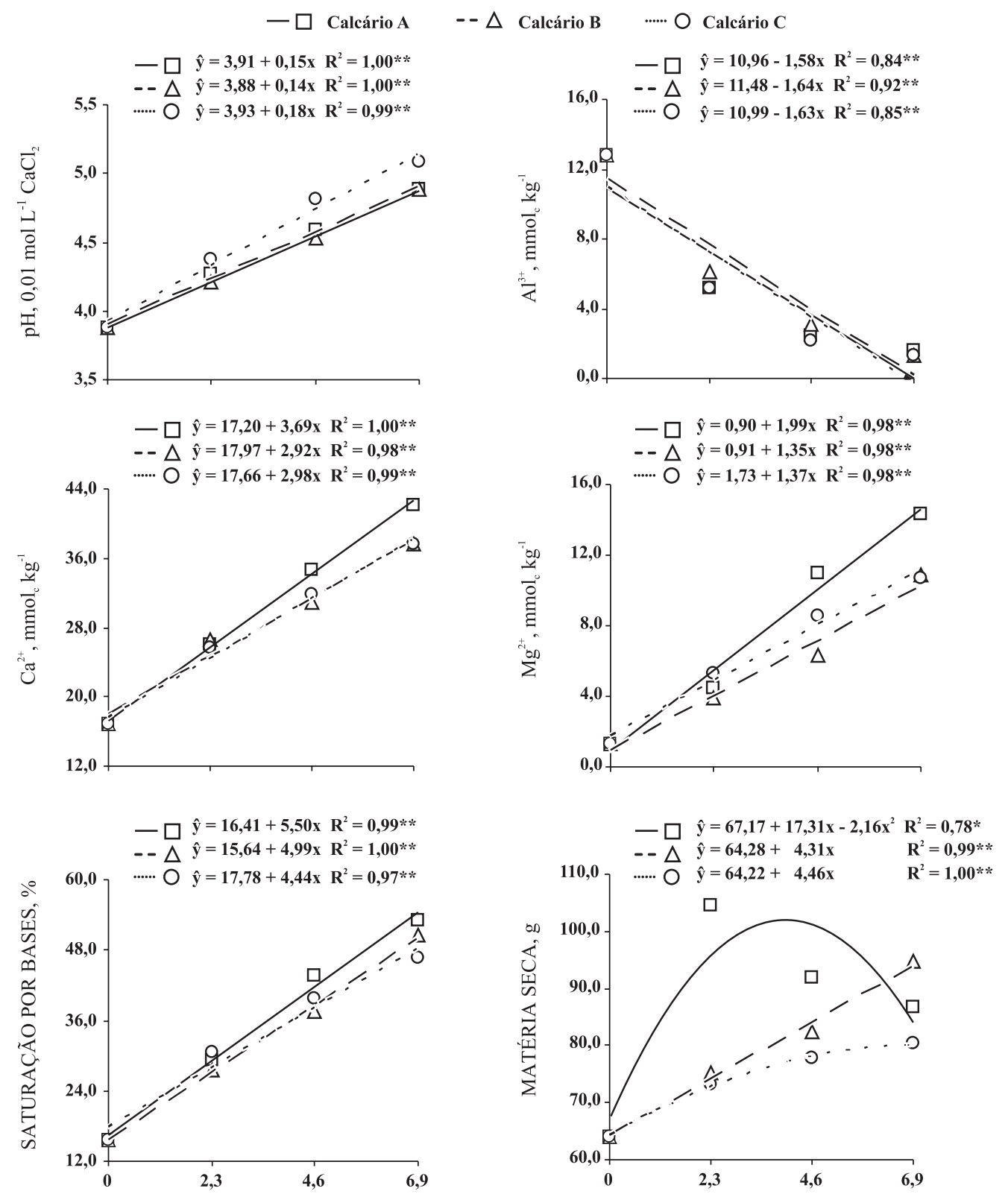

CALCÁRIO, $\mathrm{t} \mathrm{ha}^{-1}$

Figura 1. Valores de pH, teores trocáveis de Al, Ca e Mg, saturação por bases e matéria seca de plantas de milho de um Latossolo Vermelho, nos quatro ciclos da cultura do milho, em função das doses e do tipo de calcário (Quadro 1). **: $p<0,01$.

efeito residual maior, devido à sua baixa reatividade e alto poder de neutralização. Provavelmente, a presença de parte dos 16,2 \% (PN - PRNT) deste calcário, de ação mais lenta no solo, reagiu nesse período, ou seja, após os três primeiros meses no solo, ainda havia $16,2 \%$ de resíduo para continuar reagindo, ao passo que com os produtos B e C os resíduos eram de 14,8 e $1 \%$, respectivamente. Segundo Alcarde (1992), a reatividade é o percentual da ação do corretivo em um período de três meses devido à sua granulometria, e o PRNT é a quantidade do seu PN que agirá nesse período.
A calagem alterou significativamente a produção de MS da parte aérea das plantas de milho (Figuras 1 e 2). Com o uso dos calcários A e C (Quadro 1), no LV, o aumento da MS proporcionado pela calagem foi de forma quadrática, enquanto o corretivo B proporcionou aumento linear da MS. Provavelmente, com o uso dos corretivos A e C, por serem mais reativos que $\mathrm{B}$, a aplicação de altas doses tenha proporcionado desequilíbrio entres os nutrientes. A maior disponibilidade de $\mathrm{Ca}$ e $\mathrm{Mg}$ pode ter dificultado a absorção de K pelas plantas de milho. Caires et al. (2002) observaram que o aumento da relação $\mathrm{Ca}+\mathrm{Mg} /$ 

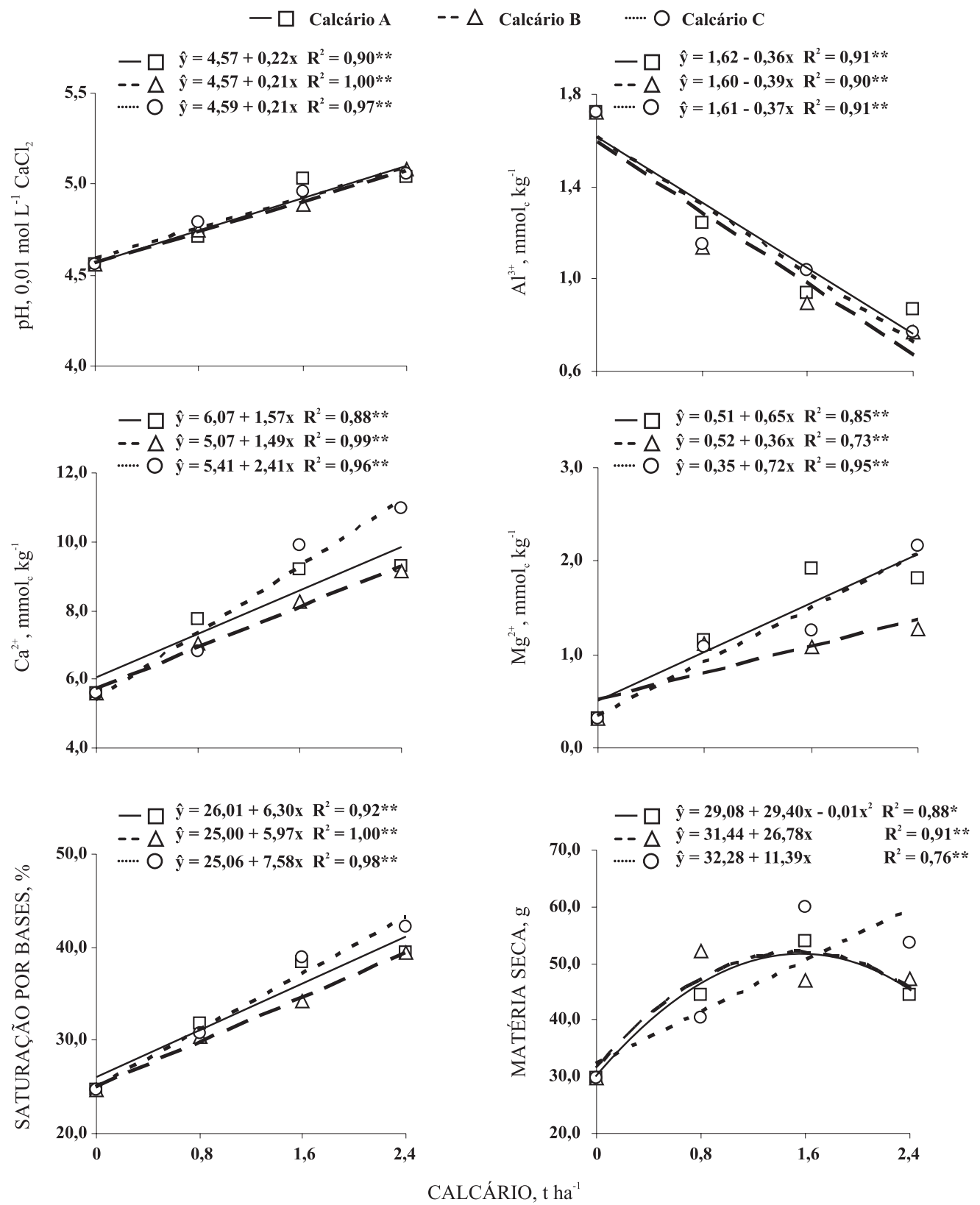

Figura 2. Valores de pH, teores trocáveis de $\mathrm{Al}$, Ca e Mg, saturação por bases e matéria seca de plantas de milho de um Neossolo Quartzarênico, nos quatro ciclos da cultura do milho, em função das doses e do tipo de calcário (Quadro 1 ). $* * * p<0,01$.

K no solo reduziu o teor de K nas folhas de milho. Devido à absorção de $\mathrm{Ca}$ e $\mathrm{Mg}$ pelas plantas e consequente redução da relação $\mathrm{Ca}+\mathrm{Mg} / \mathrm{K}$, a calagem aumentou a produção de MS de forma linear. No RQ, o maior peso seco do milho ocorreu no segundo cultivo, não havendo diferenças significativas entre os produtos testados.

Não foram observadas diferenças entre os calcários aplicados no RQ em nenhum dos ciclos para a maioria dos atributos avaliados (Figura 4). A presença de maiores concentrações de $\mathrm{Al}^{3+}$ nos dois últimos ciclos pode ter influenciado o desenvolvimento das plantas, que foi menor nesse período (Figuras 3 e 4). No entanto, não houve diferenças entres os produtos testados quanto à produção de matéria seca. Ainda assim, os corretivos apresentaram reação no solo até o último ciclo. Oliveira \& Pavan (1996) relataram redução de acidez, revelada pela elevação do $\mathrm{pH}$ e diminuição de $\mathrm{Al}^{3+}$, até $40 \mathrm{~cm}$ de profundidade após 32 meses da aplicação de calcário na superfície em sistema de cultivo sem preparo do solo. Os teores máximos de $\mathrm{Al}^{3+}$ foram observados no último ciclo de cultivo, os quais são resultados do processo extrativo (absorção) das plantas de milho, uma vez que a aplicação de calcário foi feita apenas antes da primeira semeadura. 

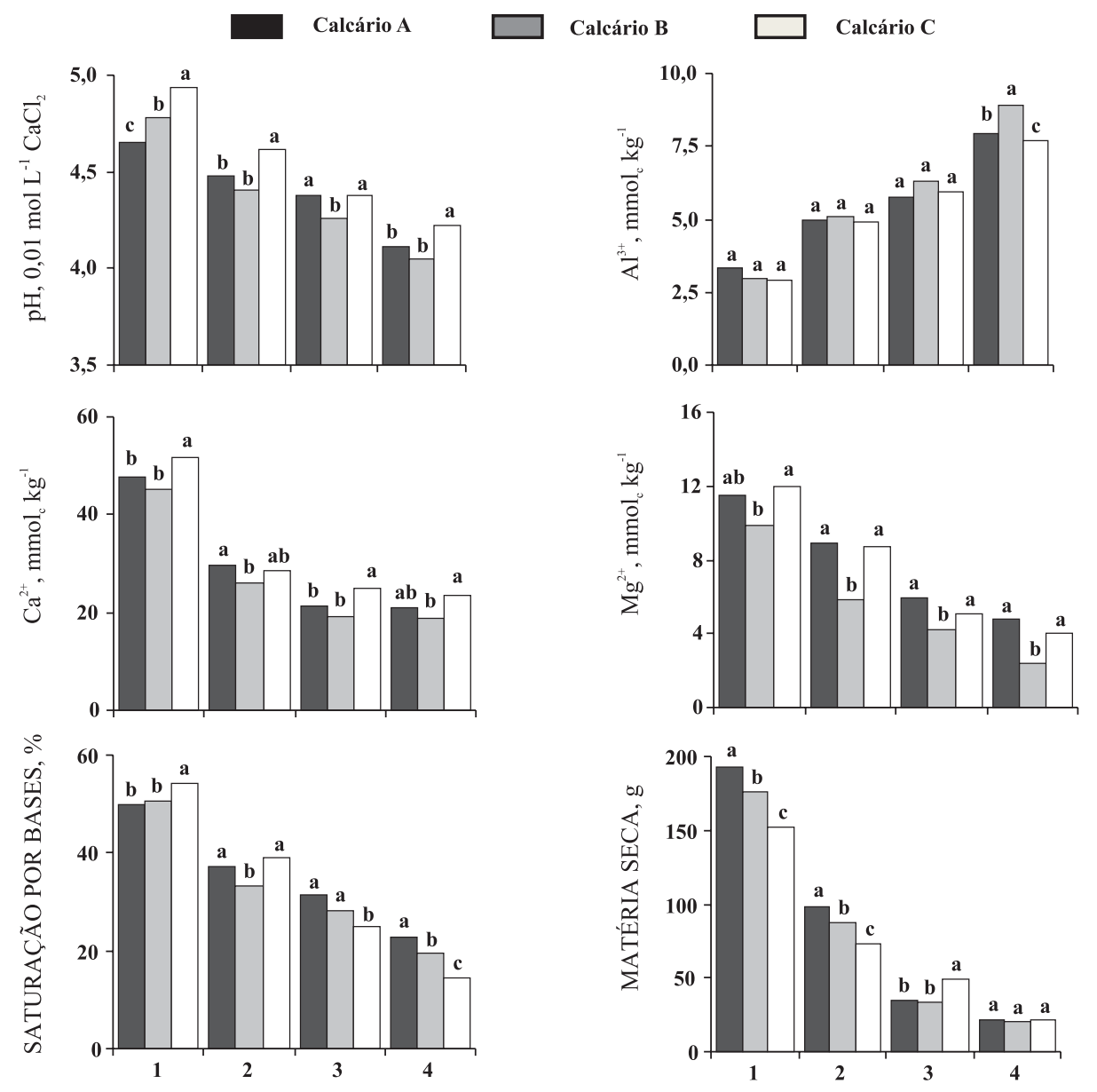

CICLOS DE CULTIVO

Figura 3. Valores de pH, teores trocáveis de $\mathrm{Al}$, Ca e Mg, saturação por bases e matéria seca de plantas de milho de um Latossolo Vermelho, em função dos tipos de calcário (Quadro 1) e dos ciclos de cultivo da cultura do milho. Letras iguais para os tipos de calcário dentro de cada ciclo de cultivo não diferem entre si pelo teste de Tukey $(p=0,05)$.

Para o RQ, entre os produtos testados, de maneira geral, o $\mathrm{C}$ forneceu a maior concentração de Ca durante os quatro cultivos, seguido do A e B; houve redução nesses valores com o decorrer dos ciclos. A maior concentração de $\mathrm{Ca}$ no solo foi observada com a aplicação do produto B para elevar a saturação por bases a $80 \%$. No entanto, maiores teores desse elemento até o segundo cultivo foram verificados com o uso de C (Figura 4). Após o terceiro ciclo, não houve diferenças entres os calcários testados.

No experimento de incubação, os valores obtidos para o Ca residual no LV não variaram significativamente dentro do ciclo 1. Contudo, nos dois períodos seguintes os maiores valores encontrados para esse atributo ocorreram com a utilização do calcário A, seguido de C e B (Quadro 2). Foi observada tendência de redução dos valores de Ca residual com os ciclos sucessivos, sem haver aumento dos valores de Ca trocável com o decorrer do tempo. De maneira geral, os teores de $\mathrm{Ca}^{2+}$ foram maiores quando comparados com valo- res residuais num mesmo período avaliado e tenderam a um equilíbrio, já que não havia planta para extrair os nutrientes, concordando com Soratto et al. (2008), que também encontraram maiores teores de Ca trocável que os residuais em um trabalho realizado em campo, 18 meses após aplicação de calcário na implantação do sistema de semeadura direta, indicando que a dissolução dos corretivos foi rápida. Raij et al. (1996) verificaram que, 14 meses após a incorporação de calcários com PRNT de 59 e $52 \%$, entre 21 e $36 \%$ das partículas maiores que $0,30 \mathrm{~mm}$ ainda não haviam sido dissolvidas. Para Mello et al. (2003), mesmo quando aplicado em superfície, a maior parte da fração granulométrica mais fina do calcário reage no solo em três meses, enquanto a fração com maior dimensão continua reagindo posteriormente. Segundo Quaggio et al. (1995), um calcário tradicional, com cerca de $25 \%$ de suas partículas maiores que a peneira de $0,30 \mathrm{~mm}$, sempre proporcionou maiores valores de Ca e Mg não trocáveis no solo. 

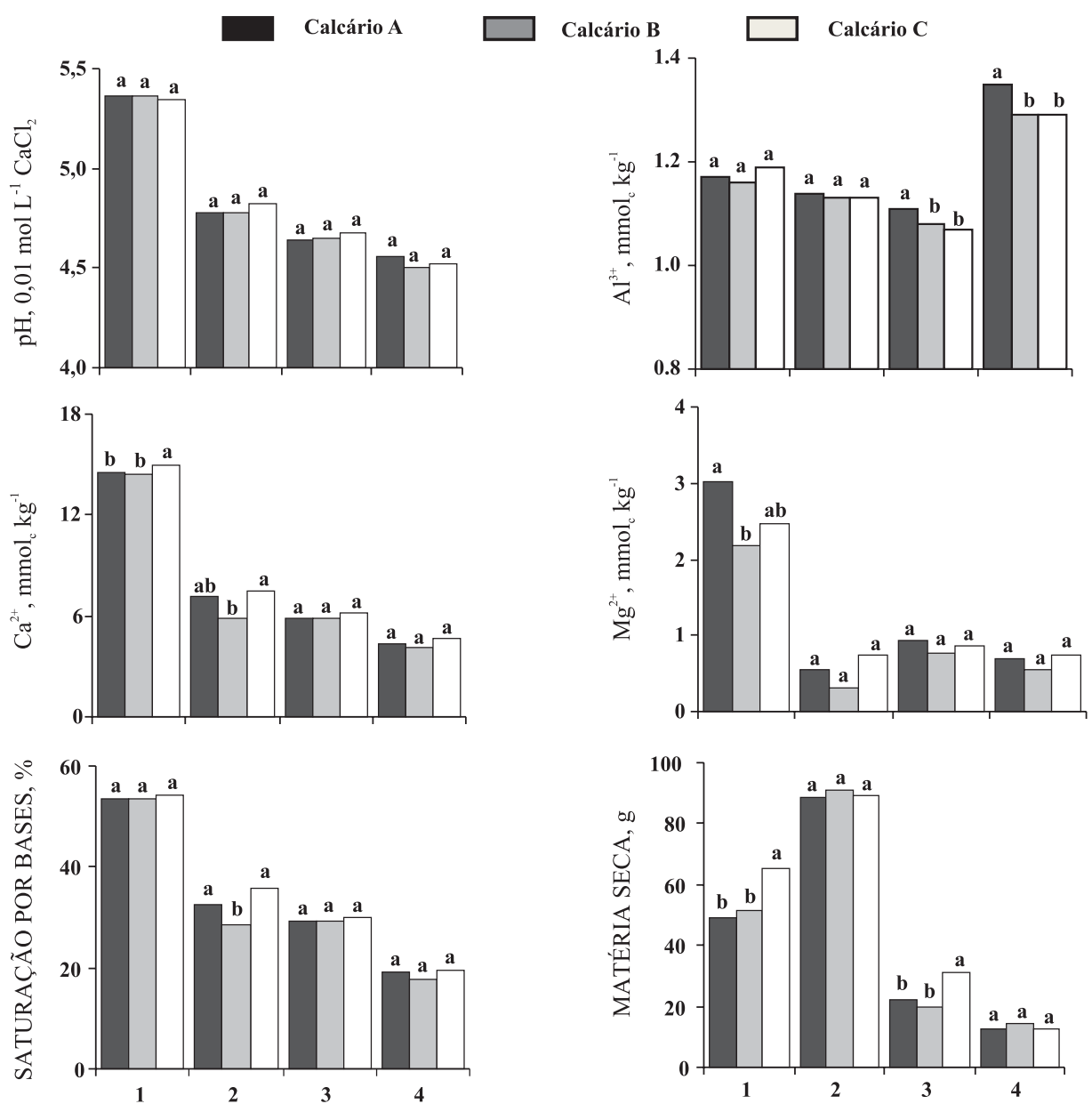

CICLOS DE CULTIVO

Figura 4. Valores de pH, teores trocáveis de $\mathrm{Al}$, Ca e $\mathrm{Mg}$, saturação por bases e matéria seca de plantas de milho de um Neossolo Quartzarênico, em função dos tipos de calcário (Quadro 1) e dos ciclos de cultivo da cultura do milho. Letras iguais para os tipos de calcário dentro de cada ciclo de cultivo não diferem entre si pelo teste de Tukey $(p=0,05)$.

Quadro 2. Efeito dos diferentes calcários, A (PRNT = 88,3 \%, RE = 85,7 \%), B (PRNT = 76,2 \%, RE = 83,7 \%) e C $($ PRNT $=105,3 \%, \mathrm{RE}=99,1 \%)$, nos teores de cálcio e magnésio trocável e residual de um Latossolo Vermelho, após três períodos de incubação. Cada ciclo correspondeu a 60 dias

\begin{tabular}{|c|c|c|c|c|c|c|}
\hline \multirow{2}{*}{ Calcário } & \multicolumn{3}{|c|}{ Ciclo } & \multicolumn{3}{|c|}{ Ciclo } \\
\hline & 1 & 2 & 3 & 1 & 2 & 3 \\
\hline & \multicolumn{6}{|c|}{$-\mathrm{mmol}_{\mathrm{c}} \mathrm{dm}^{-3}$} \\
\hline & & Ca trocável & & & Ca residual & \\
\hline A & $21,2 \mathrm{~b}$ & $20,3 \mathrm{~b}$ & $15,0 \mathrm{a}$ & $15,5 \mathrm{a}$ & $11,8 \mathrm{a}$ & $4,4 \mathrm{a}$ \\
\hline B & $24,7 \mathrm{a}$ & $24,7 \mathrm{a}$ & $16,7 \mathrm{a}$ & $14,1 \mathrm{a}$ & $7,9 \mathrm{~b}$ & $2,4 \mathrm{~b}$ \\
\hline $\mathrm{C}$ & $22,2 \mathrm{ab}$ & $21,0 \mathrm{~b}$ & $17,4 \mathrm{a}$ & $17,2 \mathrm{a}$ & $9,5 a b$ & $3,7 \mathrm{ab}$ \\
\hline Valor F & $4,8^{*}$ & $9,2^{*}$ & $2,5 \mathrm{~ns}$ & $1,4 \mathrm{~ns}$ & $4,7^{*}$ & $3,5^{*}$ \\
\hline CV (\%) & 14,6 & 14,0 & 18,8 & 33,9 & 37,1 & 64,1 \\
\hline $\mathrm{A}$ & $18,8 \mathrm{a}$ & $\begin{array}{c}\text { Mg trocável } \\
16,8 \mathrm{a}\end{array}$ & $16,5 \mathrm{a}$ & $14,4 \mathrm{~b}$ & $\begin{array}{c}\mathrm{Mg} \text { residual } \\
7,9 \mathrm{a}\end{array}$ & $13,1 \mathrm{a}$ \\
\hline $\mathrm{B}$ & $20,7 \mathrm{a}$ & $18,9 a$ & $17,3 \mathrm{a}$ & $13,7 \mathrm{~b}$ & $5,0 \mathrm{~b}$ & $12,0 \mathrm{a}$ \\
\hline $\mathrm{C}$ & $21,5 \mathrm{a}$ & $18,4 \mathrm{a}$ & $16,8 \mathrm{a}$ & $16,9 \mathrm{a}$ & $7,9 \mathrm{a}$ & $14,9 \mathrm{a}$ \\
\hline Valor F & $3,1 \mathrm{~ns}$ & $2,3 \mathrm{~ns}$ & $0,2 \mathrm{~ns}$ & $5,9^{*}$ & $7,5^{*}$ & $0,9 \mathrm{~ns}$ \\
\hline CV (\%) & 15,5 & 15,4 & 20,7 & 18,4 & 35,5 & 45,3 \\
\hline
\end{tabular}

Letras iguais dentro de um mesmo período não diferem entre si pelo teste de Tukey $(p=0,05)$. 
Quanto aos teores de Mg trocável, avaliando-se separadamente cada período, não houve diferenças significativas entre os três produtos testados (Quadro 2). Em termos gerais, observou-se tendência de esses valores se manterem constantes, com ligeira redução, assim como foi observado para os valores de $\mathrm{Ca}^{2+}$, uma vez que os teores encontrados também foram muito baixos, dificultando a comparação. Também foram verificados maiores teores de Mg trocável do que não trocável, concordando com Soratto et al. (2008). Os valores obtidos para o Mg residual do experimento de incubação variaram significativamente dentro dos dois primeiros ciclos (Quadro 2), em que os calcários A e C apresentaram maior quantidade de $\mathrm{Mg}$ sem reagir no solo. Isso pode ser explicado pelo fato de possuírem teores mais elevados desse elemento em sua constituição (Quadro 1).

No RQ foi observado comportamento semelhante em relação aos teores de Ca trocável e residual, com redução do residual e redução tendendo à estabilização do trocável (Quadro 3). O calcário C forneceu maiores quantidades de Ca e Mg trocável no primeiro e segundo ciclos. Os teores encontrados de $\mathrm{Mg}$ foram muito baixos nesses solos. Apenas com a maior dose de corretivo foi possível melhor interpretação dos resultados. Isso confirma o trabalho de Soratto et al. (2008), para os quais ainda faltam estudos para validação do método e sobre a influência de outros fatores, como a dose de calcário e, ou, a combinação com a aplicação de gesso, nos teores de Ca e Mg não trocáveis no solo, ou seja, na estimativa do calcário residual. No final do terceiro período, os teores de $\mathrm{Ca}$ e $\mathrm{Mg}$ trocáveis e residuais não diferiram significativamente.

\section{CONCLUSÕES}

1. A aplicação de calcário no Latossolo Vermelho e no Neossolo Quartzarênico estudados proporcionou aumento dos teores de $\mathrm{Ca}^{2+} \mathrm{e} \mathrm{Mg}^{2+}$ e elevação do $\mathrm{pH}$, com redução dos teores de $\mathrm{Al}^{3+}$.

2. O comportamento dos calcários A (média reatividade) e $\mathrm{C}$ (alta reatividade) foi semelhante ao avaliar os solos de textura arenosa e argilosa.

3 . Na escolha do corretivo a ser aplicado, devemse levar em consideração seus valores de PRNT, RE e $\mathrm{PN}$, a fim de analisar a viabilidade econômica de cada produto.

4. Não houve diferenças significativas entre os três produtos aplicados nos solos, na maioria dos atributos avaliados no experimento de incubação. Outros fatores, como a dose de calcário, podem ter influenciado a eficácia do método empregado.

\section{LITERATURA CITADA}

ABREU Jr., C.H.; MURAOKA, T. \& LAVORANTE, A.F. Relationship between acidity and chemical properties of Brazilian Soils. Sci. Agric., 60:337-343, 2003.

ALCARDE, J.C. Corretivos da acidez dos solos: Características e interpretações técnicas. 2.ed. São Paulo, ANDA, 1992. 26p. (Boletim Técnico, 6)

CAIRES, E. F.; PEREIRA FILHO, P. R. S. ; ZARDO FILHO, R. \& FELDHAUS, I. C. Soil acidity and aluminium toxicity as affected by surface liming and cover oat residues under a no-till system. Soil Use Manag., 24: 302-309, 2008.

Quadro 3. Efeito dos diferentes calcários, A (PRNT $=88,3 \%, \mathrm{RE}=85,7 \%), \mathrm{B}(\mathrm{PRNT}=76,2 \%, \mathrm{RE}=83,7 \%)$ e C $($ PRNT $=105,3 \%, \mathrm{RE}=99,1 \%)$, nos teores de cálcio e magnésio trocável e residual de um Neossolo Quartezarênico, após três períodos de incubação. Cada ciclo correspondeu a 60 dias

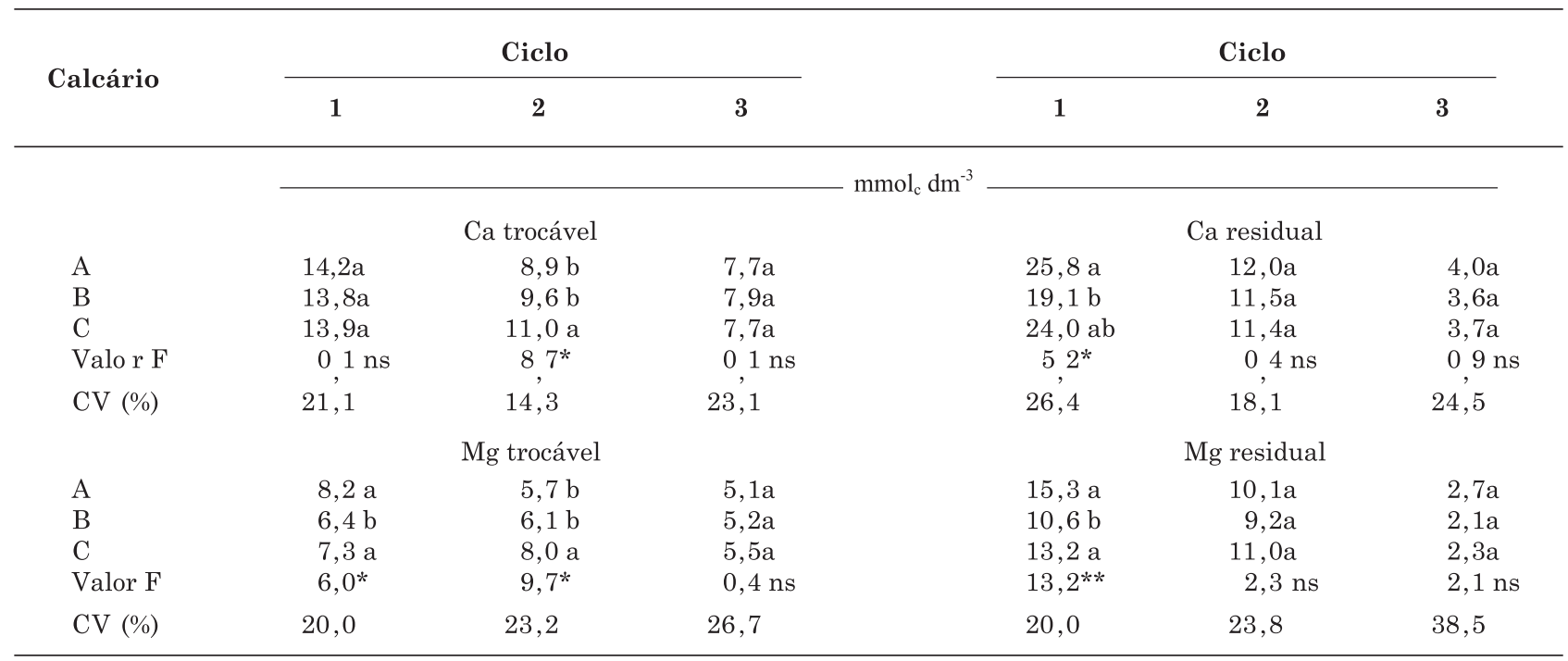

Letras iguais dentro de um mesmo período não diferem entre si pelo teste de Tukey $(p=0,05)$. 
CAIRES, E.F.; ALLEONI, L.R.F.; CAMBRI, M.A. \& BARTH, G. Surface application of lime for crop grain production under a no-till system. Agron. J., 97:791-798, 2005.

CAIRES, E.F.; BARTH, G.; GARBUIO, F.J. \& KUSMAN, M.T. Correção da acidez do solo, crescimento radicular e nutrição do milho de acordo com a calagem na superfície em sistema plantio direto. R. Bras. Ci. Solo, 26:1011-1022, 2002 .

CAMARGO, O.A.; VALADARES, J.M.A.S. \& DECHEM, A.R. Efeitos do $\mathrm{pH}$ e da incubação na extração de manganês, zinco, cobre e ferro do solo. R. Bras. Ci. Solo, 6:83-88, 1982.

CARVALHO-PUPPATTO, J.G.; BÜLL, L.T. \& CRUSCIOL, C.A.C. Atributos químicos do solo, crescimento radicular e produtividade do arroz com a aplicação de escórias. Pesq. Agropec. Bras., 39:1213-1218, 2004.

ERNANI, P.R.; NASCIMENTO, J.A.L. \& OLIVEIRA, L.C. Increase of grain and green matter of corn by liming. R. Bras. Ci. Solo, 22:275-280, 1998 .

EVANS, C.C. \& GRIMSHAW, H.M. Use of lanthanum and sulphuric acid to suppress interferences in the flame photometric determination of calcium in soils extracts. Talanta, 15:413-425, 1968.

FAGERIA, N.K. \& STONE, L.F. Manejo da acidez dos solos de cerrado e de várzea do Brasil. Santo Antônio de Goiás, Embrapa Arroz e Feijão, 1999. 42p. (Embrapa Arroz e Feijão. Documentos, 92)

FORESTIERI, E.F. \& DE-POLLI, H. Calagem, enxofre e micronutrientes no crescimento do milho e da mucuna preta num Podzólico Vermelho-amarelo. R. Bras. Ci. Solo, 14:167-172, 1990.

GONZALEZ-ERICO, E.; KAMPRATH, E.J.; NADERMAN, G.C. \& SOARES, W.V. Effect of depth of lime incorporation on the growth of corn on an Oxisol of Central Brazil. Soil Sci. Soc. Am. J., 43:1155-1158, 1979.

GOODROAD, L.L. \& JELLUM, M.D. Effect of $\mathrm{N}$ fertilizer rate and soil pH on N efficiency in corn. Plant Soil, 106:85-89, 1988.

KINRAIDE, T.B. Identity of the rhizotoxic aluminum species. Plant Soil, 34:167-178, 1991.

LIMA, E.V. Plantas de cobertura e calagem superficial na fase de implantação do sistema de plantio direto em região de inverno seco. Botucatu, Universidade Estadual Paulista, 2004. 125p. (Tese de Doutorado)

LUTZ Jr., J.A.; GENTER, C.F. \& HAWKINS, G.W. Effect of soil $\mathrm{pH}$ on element concentration and uptake by maize: I. P, K, Ca, Mg and Na. Agron. J., 64:581-583, 1972.

MALAVOLTA, E. Elementos de nutrição mineral de plantas. São Paulo, Agronômica Ceres, 1980. p.219-251.

MALAVOLTA, E.; VITTI, G.C. \& OLIVEIRA, S.A. Avaliação do estado nutricional das plantas: Princípios e aplicações. Piracicaba, Associação Brasileira para Pesquisa da Potássio e do Fosfato, 1984.
MELLO, J.C.A.; VILLAS BOAS, R.L.; LIMA, E.V.; CRUSCIOL, C.A.C. \& BULL, L.T. Alterações nos atributos químicos de um Latossolo distroférrico decorrentes da granulometria e doses de calcário em sistemas plantio direto e convencional. R. Bras. Ci. Solo, 27:553-561, 2003.

MOREIRA, S.G.; KIEHL, J.C.; PROCHNOW, L.I. \& PAULETTI, V. Calagem em sistema de semeadura direta e efeitos sobre a acidez do solo, disponibilidade de nutrientes e produtividade de milho e soja. R. Bras. Ci. Solo, 25:71-81, 2005.

NWACHUKU, D.A. \& LOGANATHAN, P. The effect of liming on maize yield and soil properties in Southern Nigeria. Comm. Soil Sci. Plant Anal., 22:623-639, 1991.

OLIVEIRA, E.L. \& PAVAN, M.A. Control of soil acidity in non tillage system for soybean production. Soil Till. Res., 38:47$57,1996$.

QUAGGIO, J.A.; GALLO, P.B. \& MASCARENHAS, H.A.A. Agronomic efficiency of limestone with different acidneutralizing capacity: under field condition. In: SYMPOSIUM ON PLANT - SOIL INTERATIONS AT LOW pH, 3., 1995. Brisbane, Proceedings. Dordrecht, Kluwer Academic, 1995. p.491-496.

QUAGGIO, J.A.; MASCARENHAS, H.A.A. \& BATAGLIA, O.C. Resposta da soja à aplicação de doses crescentes de calcário em Latossolo Roxo distrófico de cerrado. II - Efeito Residual. R. Bras. Ci. Solo, 6:113-118, 1982.

RAIJ, B. van; QUAGGIO, J.A. \& SILVA, N.M. Extraction of phosphorus, potassium, calcium and magnesium from soils by an ion-exchange resin procedure. Comm. Soil Sci. Plant Anal., 17: 547-566, 1986.

RAIJ, B. van; QUAGGIO, J.A.; CANTARELLA, H.; FERREIRA, M.E.; LOPES, A.S. \& BATAGLIA, O.C. Análise química do solo para fins de fertilidade. Campinas, Fundação Cargill, 1987. 170p.

RAIJ, B.van \& QUAGGIO, J.A. Métodos de análise de solo para fins de fertilidade. Campinas, IAC, 1983. p.1-31. (Boletim Técnico, 81)

RAIJ, B.van.; CANTARELlA, H.; QUAGGIO, J.A. \& FURLANI, A.M.C. Recomendações de adubação e calagem para o Estado de São Paulo. Campinas, Instituto Agronômico/Fundação IAC, 1996. 285p.

RAIJ, Bernardo Van; CANTARELLA, M.V.; CAMARGO, A.D. \& SOARES, E. Perdas de cálcio e magnésio durante cinco anos em ensaio de calagem. R. Bras. Ci. Solo, 6:3337, 1982.

VITTI, G.C. \& LUZ, P.H.C. Calagem e uso do gesso agrícola em pastagens. In: SIMPÓSIO SOBRE ECOSSISTEMA DE PASTAGENS, 3., Jaboticabal, 1997. Anais. Jaboticabal, 1997. p.63-111.

WERNER, J.C. Calagem para plantas forrageiras. In: SIMPÓSIO SOBRE MANEJO DE PASTAGENS, 8., Piracicaba, 1986. Anais. Piracicaba, FEALQ, 1986. p.191198. 